\title{
Inhibition of gamma ray-induced apoptosis by stimulatory heterotrimeric GTP binding protein involves Bcl-xL down-regulation in SH-SY5Y human neuroblastoma cells
}

\author{
So-Young Kim ${ }^{1}$, Miran Seo ${ }^{1}$, Jung-Min $\mathrm{Oh}^{1}$, \\ Eun-Ah Cho ${ }^{1}$ and Yong-Sung Juhnn ${ }^{1,2}$ \\ ${ }^{1}$ Department of Biochemistry and Molecular Biology \\ Cancer Research Institute, Seoul National University \\ College of Medicine, Seoul 110-799, Korea \\ ${ }^{2}$ Corresponding author: Tel, 82-2-740-8247; \\ Fax, 82-2-744-4534; E-mail, juhnn@ @snu.ac.kr
}

Accepted 18 July 2007

Abbreviations: Gas, alpha subunit of stimulatory G proteins; GPCR, $\mathrm{G}$ protein-coupled receptor

\begin{abstract}
Heterotrimeric GTP-binding proteins (G proteins) transduce extracellular signals into intracellular signals by activating effector molecules including adenylate cyclases that catalyze cAMP formation, and thus regulate various cellular responses such as metabolism, proliferation, and apoptosis. cAMP signaling pathways have been reported to protect cells from ionizing radiation-induced apoptosis, but however, the protective mechanism is not clear. Therefore, this study aimed to investigate the signaling molecules and the mechanism mediating the anti-apoptotic action of cAMP signaling system in radiation-induced apoptosis. Stable expression of a constitutively active mutant of $\mathrm{G} \alpha \mathbf{s}(\mathrm{G} \alpha \mathrm{s} \mathrm{QL})$ protected gamma ray-induced apoptosis which was assessed by analysis of the cleavages of PARP, caspase-9, and caspase-3 and cytochrome $C$ release in SH-SY5Y human neuroblastoma cells. $\mathrm{G} \alpha \mathrm{sQL}$ repressed the gamma ray-induced down-regulation of $\mathrm{Bcl}-\mathrm{xL}$ protein, but transfection of $\mathrm{Bcl}-\mathrm{xL}$ siRNA increased the gamma ray-induced apoptosis and abolished the anti-apoptotic effect of $\mathrm{G} \alpha \mathrm{sQL}$. $\mathrm{G} \alpha \mathrm{sQL}$ decreased the degradation rate of Bcl-xL protein, and it also restrained the decrease in Bcl-xL mRNA by increasing the stability following ionizing irradiation. Furthermore, prostaglandin E2 that activates $\mathrm{G} \alpha \mathrm{s}$ was found to protect gamma ray-induced apoptosis, and the protective effect was abolished by treatment with prostanoid receptor antagonist specific to EP2/4R subtype. Moreover, specific agonists for adenosine A1
\end{abstract}

receptor that inhibits cAMP signaling pathway augmented gamma ray-induced apoptosis. From this study, it is concluded that $\mathrm{G} \alpha$ s-cAMP signaling system can protect SH-SY5Y cells from gamma ray-induced apoptosis partly by restraining down-regulation of Bcl-xL expression, suggesting that radiation-induced apoptosis can be modulated by GPCR ligands to improve the efficiency of radiation therapy.

Keywords: apoptosis; bcl-x protein; cyclic AMP; gamma rays; heterotrimeric GTP-binding proteins; GTPbinding protein $\alpha$ subunits, Gs; receptors, G-protein-coupled

\section{Introduction}

The heterotrimeric GTP-binding proteins (G proteins) are composed of $\alpha, \beta$ and $\gamma$ subunits, and are classified, based on the primary sequences of $\alpha$ subunit of $G$ protein $(G \alpha)$ subunits, into four main families: $G \alpha s, G \alpha i, G \alpha q$, and $G \alpha 12$. A wide range of external stimuli, including neurotransmitters, growth factors, hormones, light, odorants, and certain taste ligands, can activate specific members of $G$ proteins-coupled receptor (GPCR) family, which induce a conformational change of the coupled $G$ protein to cause exchange of GDP with GTP in the $\alpha$ subunit, and thus dissociation of $\alpha$ and $\beta \gamma$ heterodimer $(G \beta \gamma)$ (Neer, 1995). The GTP-bound $G \alpha$ and $G \beta \gamma$ regulate a wide variety of intracellular signaling pathways including adenylate cyclases, phospholipases, phosphodiesterases, and ion channels to transduce extracellular signals into intracellular signals (Gilman, 1987). The $\mathrm{G} \alpha$ bound GTP is hydrolyzed to GDP by intrinsic GTPase, a process that is regulated by RGS (regulator of G-protein signaling), which leads to reassociation of the $\mathrm{G} \alpha \beta \gamma$ heterotrimer and termination of the activation cycle (McCudden et al., 2005).

Radiation therapy, together with surgery and chemotherapy, forms the major treatment modality for various cancers, and it can be used alone or together with chemotherapy to produce cure of localized tumors and control of the primary site of tumors that have disseminated. Ionizing radiation induces cancer cell death via various mechanisms 
including apoptosis. However, development of radioresistance of tumor cells results in unsuccessful treatment, and thus understanding the mechanisms for cell death and development of radioresistance is essential for improving the efficiency of radiotherapy for cancer. Ionizing radiation has been shown to regulate expression and activity of various molecules involved in cell death including $\mathrm{Bcl}-2$ family proteins in a variety of cancer cell lines (Findley et al., 1997). Bcl-2 family proteins are classified according to their effects on cellular apoptosis, as anti-apoptotic proteins and pro-apoptotic proteins. The anti-apoptotic members include $\mathrm{Bcl}-2, \mathrm{Bcl}-\mathrm{xL}, \mathrm{Bfl}-1, \mathrm{Bcl}-\mathrm{W}$, and $\mathrm{Mcl}-1$, and the pro-apoptotic members include Bax, Bak, and Bik. Ionizing radiation induces an increase in Bax expression, and the activated Bax/Bak induces apoptosis by allowing outer mitochondrial membrane permeabilization and release of cytochrome C which leads to activation of caspase-9 and caspase-3 (Morrison et al., 2005). lonizing radiation also induces a decrease in $\mathrm{Bcl}-2$ and $\mathrm{Bcl}-\mathrm{xL}$, which can inhibit the apoptosis induced by various cytotoxic drugs (Huang et al., 1997).

Apoptosis is regulated by various cellular signaling systems including CAMP signaling pathway. Production of CAMP from ATP is catalyzed by adenylate cyclases, which are activated by stimulatory $G$ proteins (Gs) but inhibited by inhibitory $G$ proteins (Gi). CAMP binds and activates CAMPdependent protein kinase (PKA), which phosphorylates various target proteins that contribute to regulation of a variety of cellular responses including apoptosis (Koyama et al., 2001). Increased cAMP levels were reported to exert protective effects against radiation-induced apoptosis (Lehnert, 1975), and the Gas-mediated signaling also protected reactive oxygen species induced apoptosis (Lewerenz et al., 2003). Inhibition of PKA enhanced the cytotoxic effects of ionizing radiation in radioresistant cells by inhibiting prosurvival signaling molecules such as Bcl-2 (Tortora and Ciardiello, 2002; Chin et al., 2005).

However, the underlying molecular mechanism of the protective effect of Gas-cAMP signaling pathways against ionizing radiation-induced apoptosis is not clearly known. Thus, we aimed to investigate the molecular mechanism for GascAMP signaling pathways to inhibit radiationinduced apoptosis in this study, and found that Gas inhibits gamma ray-induced apoptosis by restraining Bcl-xL down-regulation in SH-SY5Y human neuroblastoma cells.

\section{Materials and Methods}

\section{Cell culture and reagents}

SH-SY5Y human neuroblastoma cells were purchased from the American Type Culture Collection (ATCC, Manassas, VA), and maintained in DMEM containing 10\% FBS (JBI, Korea) and $100 \mathrm{U} / \mathrm{ml}$ penicillin/streptomycin, in a $5 \% \mathrm{CO}_{2}$ incubator at $37^{\circ} \mathrm{C}$. SH-SY5Y cells stably expressing constitutively active mutant $\mathrm{G} \alpha \mathrm{s}$ (GasQ227L) were established in previous study (Jang and Juhnn, 2001). $\mathrm{N}$-acetyl-L-cysteine (NAC), actinomycin $\mathrm{D}, \mathrm{AH}$ 6809, AH23848, 2-chloro-N(6)-cyclopentyladenosine (CCPA), cycloheximide, DMSO, prostaglandin E2 (PGE2), R-phenylisopropyl-adenosine (R-PIA) and SC19220 were purchased from Sigma (St. Louise, MO).

\section{Measurement of CAMP accumulation}

cAMP levels were determined by competitive binding with $[3 \mathrm{H}] \mathrm{CAMP}$ to a CAMP binding protein, the regulatory subunit Rla of CAMP dependent protein kinase which was expressed in E. coli. In brief, the culture medium was removed from a 12-well plate containing the SH-SY5Y neuroblastoma cells, and cAMP was extracted by immediate addition of $2.5 \mathrm{M}$ perchloric acid. After the acid extract was neutralized with $4.2 \mathrm{M} \mathrm{KOH}$, cAMP levels were determined by competitive binding with $[3 \mathrm{H}] \mathrm{CAMP}$ to the CAMP binding protein, and cAMP levels were normalized to the amount of acidinsoluble protein.

\section{Irradiation with gamma ray}

Cells were plated in $10-\mathrm{cm}$ dishes and incubated until $80 \%$ confluent. Cells were then exposed to gamma-rays from a ${ }^{137} \mathrm{Cs}$ source at a delivering dose rate of $246.5 \mathrm{cGy} / \mathrm{min}$.

\section{Cell viability assay}

Cells $(5,000$ cells/well in 96 -well plates, $100 \mu \mathrm{l})$ were exposed to 0-30 Gy of gamma ray. After $24 \mathrm{~h}$, cells were incubated with $0.5 \mathrm{mg} / \mathrm{ml}$ MTT for $2 \mathrm{~h}$. Absorption at $595 \mathrm{~nm}$ was measured after solubilization of the formazan crystals with DMSO. Assays were performed in triplicate, and mean cell viability was compared to DMSO-treated controls.

\section{Flow cytometric analysis of Annexin V stained cells}

Apoptosis was quantified using Annexin V-FITC apoptosis kits (BD Biosciences, San Diego, CA) according to the manufacturer's instructions. 
Stained cells were analyzed using a FACSCalibur flow cytometer and the CellQuest analysis program (BD Biosciences, NorthRyde, Australia).

\section{Construction and transfection of $\mathrm{Bcl}-\mathrm{xL}$ small interference RNA (siRNA)}

Double strand DNA coding Bcl-xL siRNA was prepared by annealing the chemically synthesized oligonucleotides having complementary sequences; a forward primer 5'-CACCGCAGGGACAGCATATCAGAGCGAACTCTGATATGCTGTCCCTG-3', a reverse primer 5'-AAAACAGGGACAGCATATCAGAGTTCGCTCTGATATGCTGTCCCTGC-3'. The double stand DNA was inserted into pENTR/ $\mathrm{H} 1 / \mathrm{TO}$ vector to generate the $\mathrm{pENTR/H1/TO-Bcl-}$ $\mathrm{xL}$ siRNA construct using BLOCK-iTTM Inducible H1 RNAi Entry Vector Kit (Invitrogen, Carlsbad, CA). Transfection of $p E N T R / H 1 / T O-B c l-x L$ siRNA was performed by electroporation using a Gene Pulser II (Bio Rad, Hercule, CA) at $250 \mathrm{~V} / 950 \mu \mathrm{F}$, and the transfected cells were allowed to grow at $37^{\circ} \mathrm{C}$ for $48 \mathrm{~h}$ before gamma ray irradiation.

\section{Immunoblot analysis}

Total cell lysates (50 $\mu \mathrm{g}$ of protein) was separated by 10 or $15 \%$ SDS-PAGE, transferred to nitrocellulose paper, and analyzed with specific antibodies. Antibodies against $\mathrm{Bcl}-2$, caspase- 9 and $\beta$ actin were from Santa Cruz Biotechnology (Santa Cruz, CA), antibodies against $\mathrm{Bcl}-\mathrm{xL}$, Bad, Bax, Bak, cleaved caspase-3 (Asp175) and poly-(ADPribose) polymerase (PARP) from Cell Signaling Technology (Beverly, MA). cytochrome $C$ release into cytoplasm was analyzed by subcellular fractionation (Ahn et al., 2000) followed by immunoblotting using antibody from BD Biosciences (San Diego, CA). The proteins were visualized by incubation with an enhanced chemiluminescence substrate mixture (Pierce) and then exposed to $X$-ray film (AGFA Curix RPI). The densities of visualized bands were quantified using a $\mathrm{NIH}$ Image $\mathrm{J}$ software and relative band densities were expressed as percentages of corresponding control densities.

\section{Real-time quantitative RT-PCR}

Real-time quantitative RT-PCR was performed as described previously (Cho et al., 2007). Total RNA was isolated from the harvested cells using acid guanidinium thiocyanate-phenol chloroform extraction method. First-strand cDNA was synthesized with oligo-dT as primers, using SuperScript FirstStrand Synthesis System according to manu- facturer's protocol (Invitrogen, Carlsbad, CA). PCR was performed with specific primers: $\mathrm{Bcl}-\mathrm{xL}$; a forward primer 5'-TTGGACAATGGACTGGTTGA3', a reverse primer 5'-GTAGAGTGGATGGTCAGTG-3', GAPDH; a forward primer 5'-ACCACAGTCCATGCCATCAC-3', a reverse primer 5'-TCCACCACCCTGTTGCTGTA-3'. Real-time RT-PCR was performed in a $25 \mu \mathrm{l}$ mixture composed of $200 \mathrm{nM}$ each of forward and reverse primers, and iQTM SYBR Green Supermix (Roche, Basel, Switzerland) using iCyler and $i Q$ software (Bio Rad, Hercules, CA). After 40 cycles of PCR, average threshold cycle $(\mathrm{Ct})$ values for $\mathrm{Bcl}-\mathrm{xL}$ from the triplicate $\mathrm{PCR}$ reactions were normalized against the average $\mathrm{Ct}$ values for GADPH from the same cDNA sample.

\section{Data analysis}

At least three or more independent experiments were conducted for all the analysis. The nonparametric Mann-Whitney $U$ test was used to analyze mean values, and a $P$ value of $<0.05$ was considered statistically significant.

\section{Results}

\section{G $\alpha$ s protected SH-SY5Y neuroblastoma cells from gamma ray-induced apoptosis}

To investigate the role of Gas in gamma rayinduced apoptosis, we used a SH-SY5Y human neuroblastoma cell line, which stably expresses a mutant form of $\mathrm{G} \alpha \mathrm{s}$ (GasQL) that constitutively activates adenylate cycleases (Jang and Juhnn, 2001). The expression of mutant Gas was confirmed again in this study by Western blot analysis of GasQL expression using antibodies specific for Gas, HA-tag, or phosphorylated CREB, and by measuring the basal cAMP levels; in the GasQL expressing cells cAMP level was increased from $3.4 \pm 0.6 \mathrm{pmol} / \mathrm{mg}$ protein to $28.5 \pm 0.5 \mathrm{pmol} / \mathrm{mg}$ protein $(P<0.05)$ in vector-transfected cells (data not shown).

When SH-SY5Y cells were irradiated with varying dose of gamma ray from 1 to $30 \mathrm{~Gy}$, the cell viability decreased and cleavages of caspase3 and PARP increased in a dose-dependent manner (Figure 1A). Gamma ray-irradiation (4 Gy) induced the cleavages of caspase-9, caspase-3, and PARP in SH-SY5Y cells, and the expression of GaSQL decreased the cleavages of caspase-9 $(18.5 \pm 1.4 \%, P<0.05)$, caspase-3 $(23.6 \pm$ $4.4 \%, P<0.05)$ and PARP $(28.3 \pm 1.8 \%, P<$ $0.05)$, and cytochrome $C$ release $(17.3 \pm 2.9 \%, P$ $<0.05)$ into cytosol versus vector-transfected cells 
A
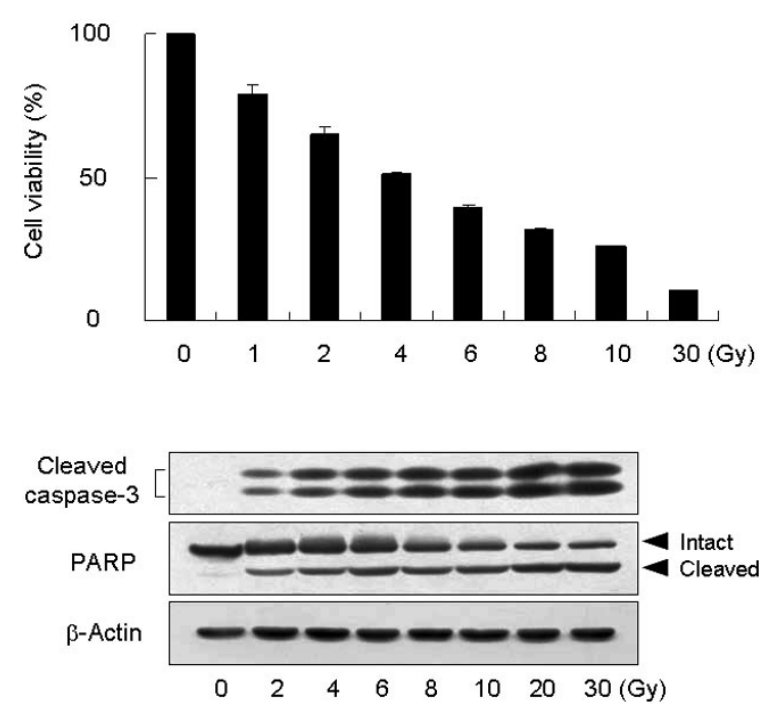

C

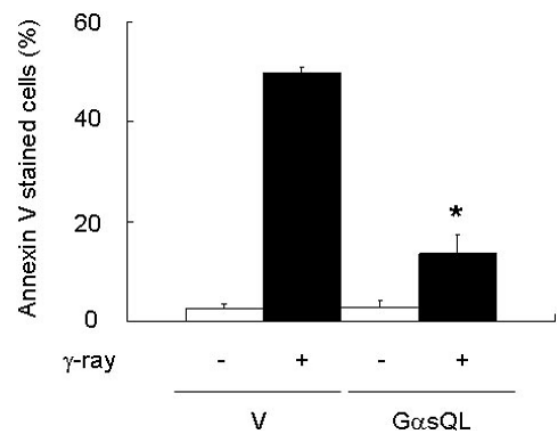

B

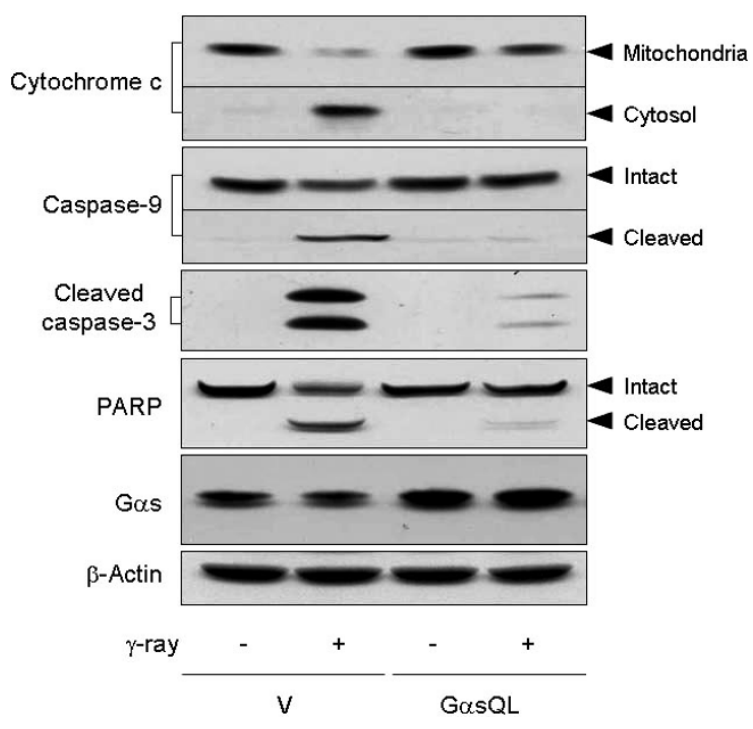

Figure 1. Effects of Gas on gamma ray-induced apoptosis of SH-SY5Y human neuroblastoma cells. (A) Effects of gamma ray irradiation dose on apoptosis of SH-SY5Y cells. SH-SY5Y cells, plated in 96-well plates (5,000 cells/well), were exposed to varying dose of gamma ray (0-30 Gy). Then, the cell viability was assessed by MTT assay and apoptosis was assessed by Western analysis of the cleavages of capspase- 3 and PARP $24 \mathrm{~h}$ after irradiation. (B, C) Effects of GasQL on gamma ray-induced apoptosis. At $24 \mathrm{~h}$ after gamma ray irradiation (4 Gy), apoptosis was assessed by Western analysis of the cleavages of caspase-9, capspase-3 and PARP (B) in vector (V)- or GasQL-expressing SH-SY5Y cells. The cytochrome $\mathrm{C}$ release into cytosol was analyzed by Western blotting after cytosolic and mitochondrial fractions were prepared by centrifugation. The histograms shows representative FACS analysis data of Annexin V stained cells $(C)$. The blots shown are representative of at least three independent experiments. Histograms represent average and \pm $\mathrm{SE}$. And the data are expressed as percentages of corresponding densities of control cells. Asterisks indicate significant difference $(P<0.05$ compared with radiation exposed cells, Mann-Whitney U-test).

$24 \mathrm{~h}$ after irradiation (Figure 1B). Stable GasQL expression reduced Annexin $\mathrm{V}$ positive cells to $13.6 \pm 3.7 \%$ from $49.9 \pm 1.0 \%(P<0.05)$ in vector transfected control following gamma ray irradiation (Figure 1C). This result suggests that Gas can protect SH-SY5Y neuroblastoma cells from gamma ray-induced apoptosis of SH-SY5Y cells.

\section{G $\alpha$ s inhibited gamma ray-induced apoptosis by restraining down-regulation of $\mathrm{Bcl}-\mathrm{xL}$ protein in SH-SY5Y neuroblastoma cells}

To study the mechanism for Gas to protect the neuroblastoma cells from gamma ray-induced apoptosis, the effects of Gas on the expression of $\mathrm{Bcl}-2$ family proteins following gamma ray irradiation was examined. Gamma ray irradiation decreased expression of anti-apoptotic $\mathrm{Bcl}-\mathrm{xL}$ protein to $59.4 \pm 1.8 \%(P<0.05)$ without changing the expression of $\mathrm{Bcl}-2$ protein. The radiation increased the expression of pro-apoptotic Bak 
A
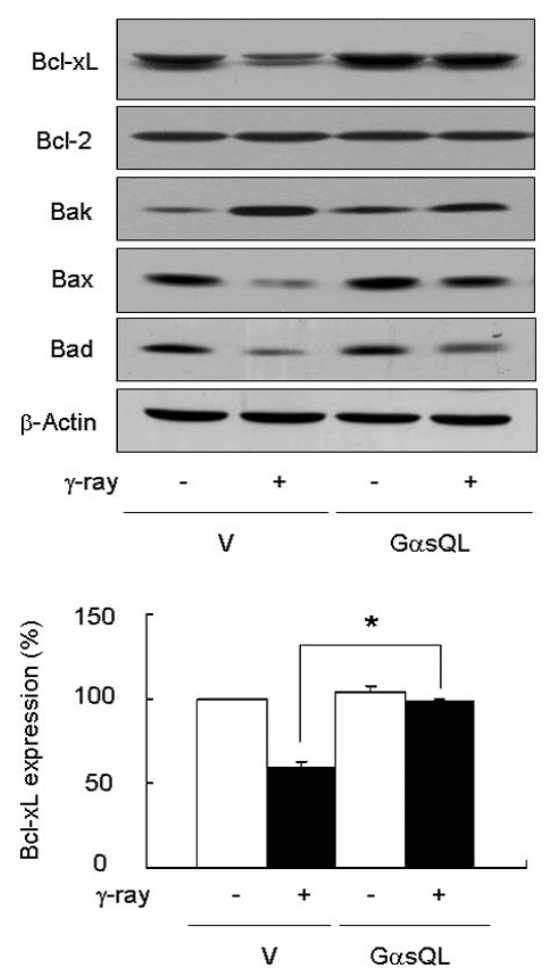

C
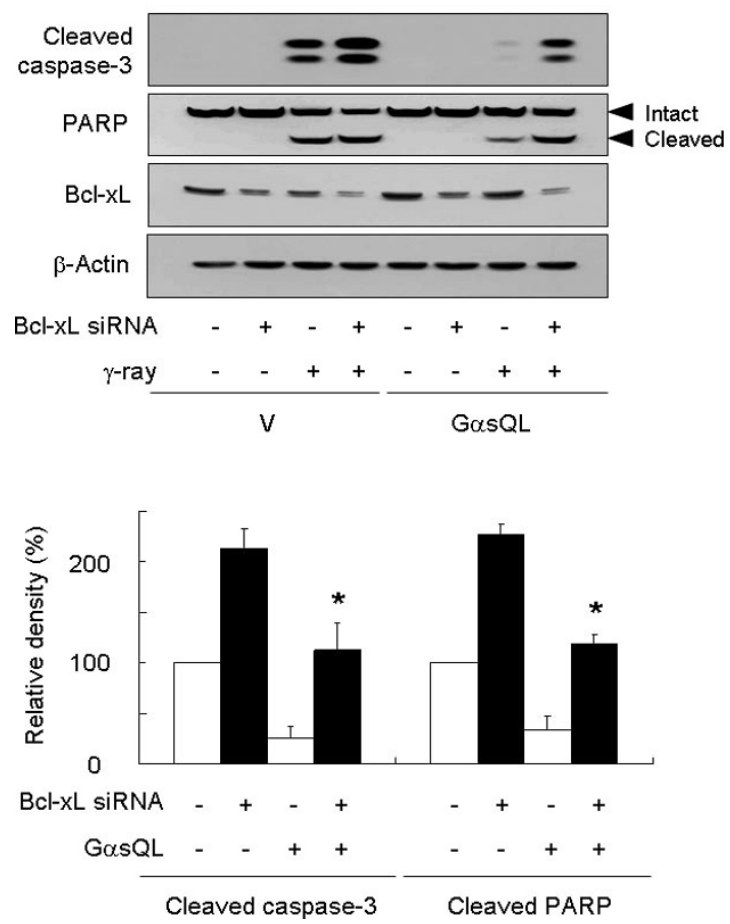

B

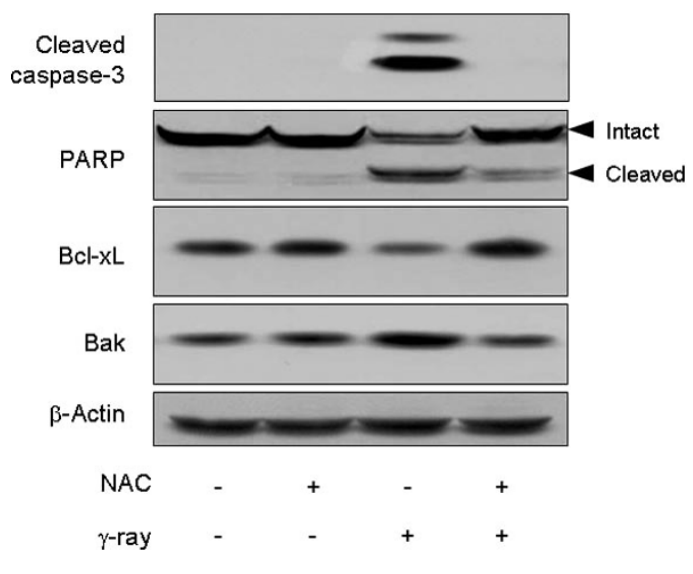

Figure 2. Involvement of $B c l-x L$ in the protective effects of $G \alpha s$ against gamma ray-induced apoptosis. (A) Effects of Gas on gamma ray-induced expression of Bcl-2 family proteins. At $24 \mathrm{~h}$ after gamma ray irradiation (4 Gy), SH-SY5Y cells were harvested and analyzed for anti-apoptotic and pro-apoptotic Bcl-2 family proteins by Western blotting. The blots shown are representative of at least three independent experiments. Histograms represent means and $\pm \mathrm{SE}$ of the relative density of $\mathrm{Bcl}-\mathrm{xL}$ expressed as percentages of corresponding densities of control cells in the Western blot. Asterisks indicate significant difference $(P<0.05$ compared with radiation exposed cells, MannWhitney U-test). (B) Effects of antioxidant on gamma ray-induced apoptosis of SH-SY5Y cells. Cells were pretreated with $100 \mu \mathrm{M}$ NAC for $30 \mathrm{~min}$ and then exposed to gamma ray (4 Gy). Apoptosis was assessed by Western analysis of the cleavages of capspase-3 and PARP, Bcl-xL and Bak $24 \mathrm{~h}$ after irradiation. (C) Effects of knockdown of $\mathrm{Bcl}-\mathrm{xL}$ on the protective effects of $\mathrm{G} \alpha \mathrm{S}$ against gamma ray-induced apoptosis. SH-SY5Y cells were transfected with $15 \mu \mathrm{g}$ of Bcl-xL plasmid (pENTR-Bcl-xL siRNA) of vector control ( $p E N T R-l a c Z$ ) by electroporation. At $48 \mathrm{~h}$ after transfection, cells were irradiated with gamma ray (4 Gy), and then apoptosis were assessed after $24 \mathrm{~h}$ by Western blotting. Data are expressed as percentages of corresponding densities of control cells and the histograms represent mean \pm SE. Asterisks indicate significant differences $(P<0.05$ compared with radiation exposed cells, Mann-Whitney U-test). 
protein to $3.1 \pm 0.3$-fold $(P<0.05)$, but decreased the expression of $\operatorname{Bax}(34.6 \pm 1.2 \%, P<$ $0.05)$ and Bad proteins (44.1 $\pm 1.4 \%, P<0.05)$. The stable expression of GasQL restored the gamma ray-induced decrease in $\mathrm{Bcl}-\mathrm{xL}$ expression to $98.3 \pm 1.7 \%$ of the un-irradiated control without affecting $\mathrm{Bcl}-2$ expression. In addition, expression of GasQL increased the basal level of Bak by $1.5 \pm$ 0.2 -fold $(P<0.05)$, but reduced the gamma rayinduced expression of Bak to $1.7 \pm 0.1$-fold $(P<$ $0.05)$ of the untreated vector control level. The expression of GasQL showed a tendency to increase the basal and gamma ray-induced expression of Bax and Bad proteins in comparison to vector-transfected control (Figure 2A). Because ionizing radiation induces production of ROS, the effect of ROS on the gamma ray induced apoptosis was analyzed. Pretreatment with an antioxidant $\mathrm{N}$ acetyl-L-cysteine (NAC) effectively blocked the gamma ray-induced decrease in $\mathrm{Bcl}-\mathrm{xL}$ expression and the increase in Bak expression (Figure 2B). NAC treatment also significantly reduced gamma ray-induced cleavages of caspase- 3 and PARP, suggesting that ROS mediates the apoptotic cell death induced by the gamma ray irradiation.

Next, to confirm the role of $\mathrm{Bcl}-\mathrm{xL}$ in the protective effect of $\mathrm{G} \alpha \mathrm{s}$ against gamma ray-induced apoptosis, the expression of $\mathrm{Bcl}-\mathrm{xL}$ was knockdown by siRNA method. The transfection of $\mathrm{Bcl}-\mathrm{xL}$ siRNA decreased the basal expression of $\mathrm{Bcl}-\mathrm{xL}$ in both the GasQL expressing cells $(65.5 \pm 1.3 \%, P$ $0.05)$ and vector-transfected cells (58.5 \pm $1.4 \%, P<0.05$ ), and it also augmented gamma ray-induced decrease in $\mathrm{Bcl}-\mathrm{xL}$ expression in both the GasQL expressing cells $(36.4 \pm 3.2 \%, P<$ $0.05)$ and vector-transfected cells $(34.9 \pm 1.5 \%, P$ $<0.05)$. Transfection of $\mathrm{Bcl}-\mathrm{xL}$ siRNA increased gamma ray-induced caspase-3 cleavage from 34.7 $\pm 4.0 \%$ to $105.6 \pm 28.1 \%(P<0.05)$ and PARP from $23.6 \pm 3.4 \%$ to $117.7 \pm 11.7 \%(P<0.05)$ in GasQL expressing cells versus gamma ray irradiated vector-transfected control (Figure 2C). This result suggests that restraining down-regulation of $\mathrm{Bcl}-\mathrm{xL}$ expression might be one mechanism for $G \alpha$ s to inhibit apoptosis induced by gamma ray irradiation in SH-SY5Y neuroblastoma cells.

\section{$\mathrm{G} \alpha \mathrm{s}$ restrained gamma ray-induced $\mathrm{Bcl}-\mathrm{xL}$ down-regulation by inhibiting the degradation of both $\mathrm{Bcl}-\mathrm{xL}$ protein and $\mathrm{mRNA}$}

To investigate the mechanism whereby $G \alpha$ s restrained the gamma ray-induced $\mathrm{Bcl}-\mathrm{xL}$ down-regulation, we first examined the degradation rate of $\mathrm{Bcl}-\mathrm{xL}$ protein. The degradation rate of $\mathrm{Bcl}-\mathrm{xL}$ protein in GasQL expressing cells was significantly slower than that in vector transfected cells, so the half-life of $\mathrm{Bcl}-\mathrm{xL}$ protein after cycloheximide treatment increased to approximately $14.4 \pm 0.2 \mathrm{~h}$ $(P<0.05)$ in $\mathrm{G} \alpha \mathrm{s}$ expressing cells from $8.0 \pm 0.2$ $h$ in vector transfected cells (Figure $3 A$ ). Next, the effect of $\mathrm{G} \alpha \mathrm{s}$ expression on the Bcl-xL mRNA level was examined. Gamma ray irradiation removed most of Bcl-xL mRNA, but the expression of GasQL preserved most of Bcl-xL mRNA after $24 \mathrm{~h}$ following the irradiation. This result was confirmed by quantitative real time RT-PCR analysis, which showed that gamma ray irradiation decreased Bcl-xL mRNA level to $14.4 \pm 6.8 \%(P<0.05)$ of the untreated vector-transfected control, and that GasQL expression increased the basal Bcl-xL mRNA level to $116.6 \pm 0.6 \%(P<0.05)$, and preserved almost intact $\mathrm{Bcl}-\mathrm{xL}$ mRNA level (100.1 \pm $10.2 \%, P<0.05$ ) following gamma ray irradiation (Figure 3B).

Then, to probe the mechanism of increased $B c l-x L$ mRNA levels, we examined the effects of Gas on the degradation of Bcl-xL mRNA after inhibition of transcription by treatment with actinomycin D. The degradation rate of Bcl-xL mRNA in GasQL expressing cells was significantly slower than that in vector transfected cells, so the half-life of Bcl-xL mRNA increased to approximately $5.5 \pm$ $0.1 \mathrm{~h}(P<0.05)$ in Gas-expressing cells from 1.1 $\pm 0.3 \mathrm{~h}$ in vector transfected cells (Figure $3 \mathrm{C}$ ). Actinomycin $D$ treatment caused a rapid decrease in Bcl-xL mRNA level to $38.9 \pm 4.9 \%(P<0.05)$ without gamma ray irradiation, and to $12.0 \pm 2.4 \%$ $(P<0.05)$ of the vector-transfected control $2 \mathrm{~h}$ after irradiation. However, GasQL expression maintained Bcl-xL mRNA level to $87.6 \pm 1.9 \%(P$

$<0.05)$ of the untreated vector-transfected control after Acinomycin $D$ treatment, and it also maintained Bcl-xL mRNA to $83.1 \pm 1.9 \%(P<0.05)$ following irradiation (Figure 3D). This result indicates that $\mathrm{G} \alpha \mathrm{s}$ restrains gamma ray-induced Bcl$\mathrm{XL}$ down-regulation by slowing down degradation of both Bcl-xL mRNA and protein.

\section{GPCR ligands modulated the gamma ray-induced apoptosis of SH-SY5Y neuroblastoma cells}

Gas was found to protect gamma ray-induced apoptosis of SH-SY5Y neuroblastoma cells by restraining down-regualtion of $\mathrm{Bcl}-\mathrm{xL}$, so, we examined whether PGE2, of which receptor activates Gas to stimulate adenylate cyclases, can also protects gamma ray-induced apoptosis. Pretreatment with PGE2 reduced gamma ray-induced caspase-3 cleavage to $28.3 \pm 9.4 \%(P<0.05)$ and PARP cleavage to $33.7 \pm 6.2 \%(P<0.05)$ of untreated control (Figure $4 A$ ). Then, the subtype of 
A
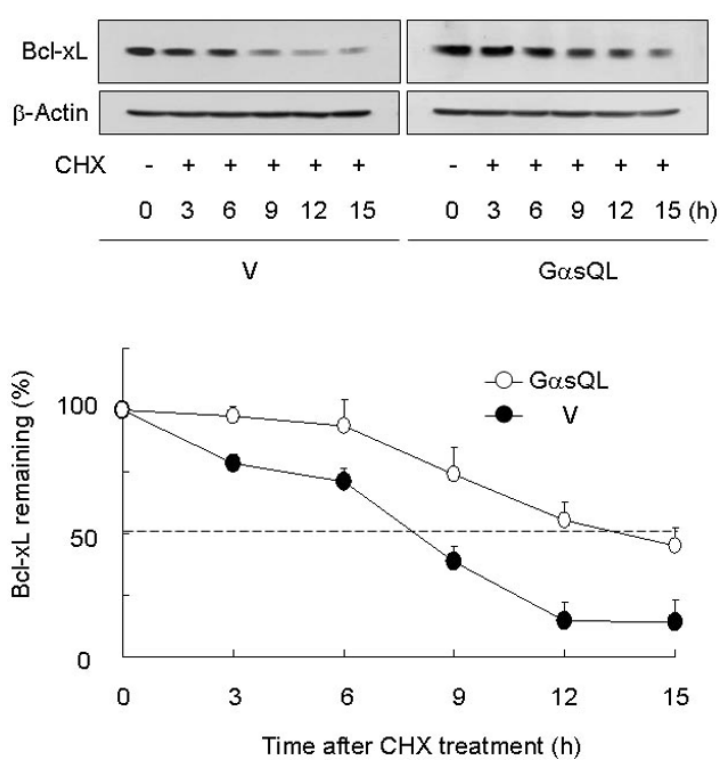

C
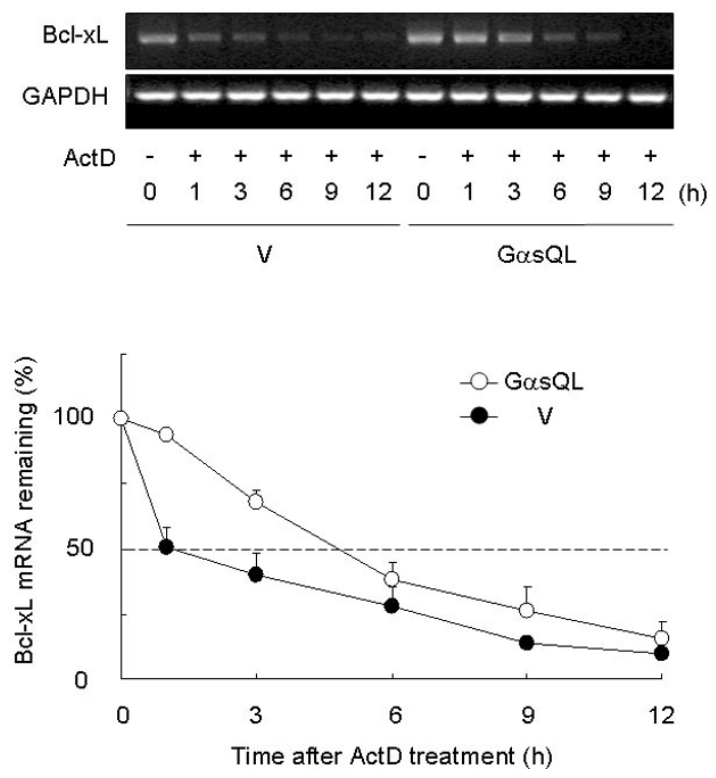

B
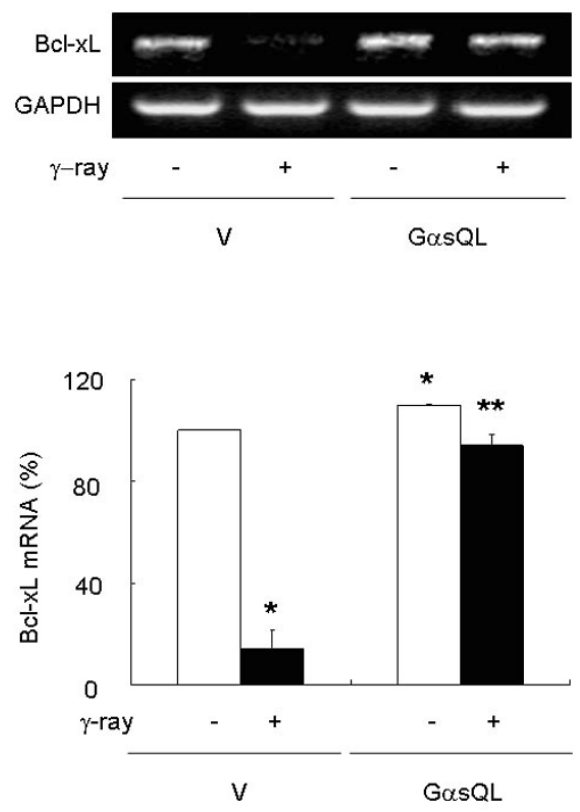

D
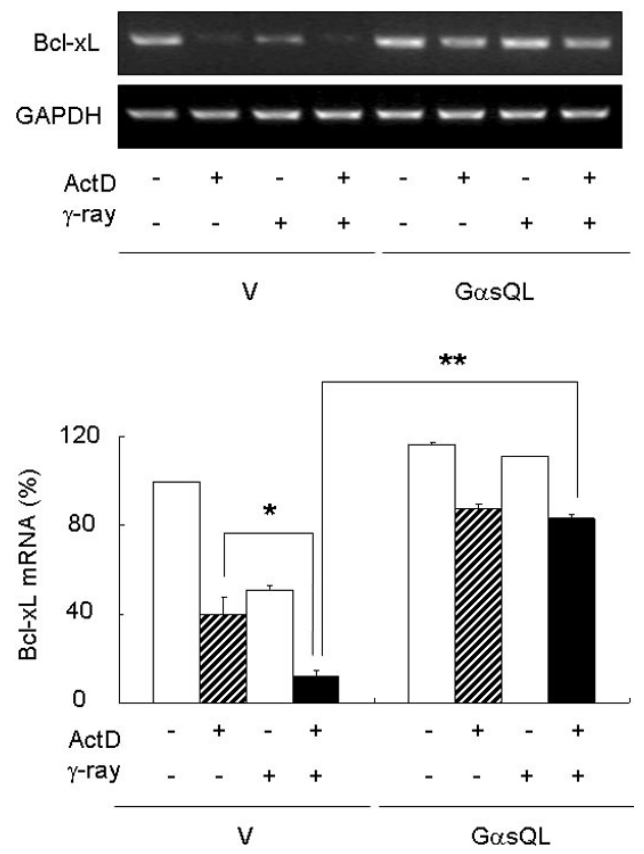

Figure 3. Effects of $\mathrm{G} \alpha$ s on the expression of Bcl-xL following gamma ray-irradiation in SH-SY5Y cells. (A) Effects of GasQL on the degradation rate of Bcl-xL protein. SH-SY5Y cells were treated with $10 \mu \mathrm{g} / \mathrm{ml}$ cycloheximide $(\mathrm{CHX})$, and Bcl-xL protein levels were quantified at various time intervals by Western blot analysis of total cell lysates. The graph shows the mean relative densities $\pm \mathrm{SE}$ of Bcl-xL bands compared to the initial density. (B) Effects of G $\alpha$ SQL on the expression of Bcl-xL mRNA. The expression Bcl-xL mRNA was analyzed at $24 \mathrm{~h}$ after gamma ray irradiation by RT-PCR, and quantified by real time RT-PCR. The amount of Bcl-xL mRNA was normalized to that of GAPDH, and presented as ratio to that of vector transfected control. The values are mean \pm SE of at least 4 independent experiments in triplicates. The asterisk (*) indicates significant difference compared to that of un-irradiated vector-transfected cells, and double asterisks ${ }^{* *}$ ) indicate significant difference compared to that of irradiated vector-transfected cells. (C) Effects of GasQL on the degradation of Bcl-xL mRNA. The cells were treated with $1 \mu \mathrm{g} / \mathrm{ml}$ actinomycin $\mathrm{D}$, and Bcl-xL mRNA levels quantified at various time intervals by RT-PCR analysis of total cell lysates. (D) Effects of GaSQL on the gamma ray-induced degradation of Bcl-xL mRNA. SH-SY5Y cells were irradiated with gamma ray (4 Gy), and then immediately treated with $1 \mu \mathrm{g} / \mathrm{ml}$ actinomycin D. Cells were harvested after $2 \mathrm{~h}$ for RT-PCR analysis. The graph shows the mean relative densities ( $\pm \mathrm{SE}$ ) of Bcl-xL bands compared to the initial density. The asterisk ${ }^{*}$ ) indicates significant difference compared to that of actinomycin $D$ treated cells, and double asterisks $\left.{ }^{* *}\right)$ indicate significant difference compared to that of actinomycin D-treated irradiated vector-transfected cells $(P<0.05$, Mann-Whitney U-test). 
PGE2 receptors involved in anti-apoptotic effects of PGE2 was examined. Co-treatment of PGE2 together with $\mathrm{AH} 6809$, an EP1/EP2 mixed prostanoid receptor antagonist increased gamma ray- induced caspase-3 cleavage to $251.6 \pm 35.1 \%(P$ $<0.05)$, and PARP cleavage to $205.6 \pm 5.3 \%(P$ $<0.05)$, respectively in SH-SY5Y cells. Similarly, co-treatment of PGE2 together with $\mathrm{AH} 23848$, an

A
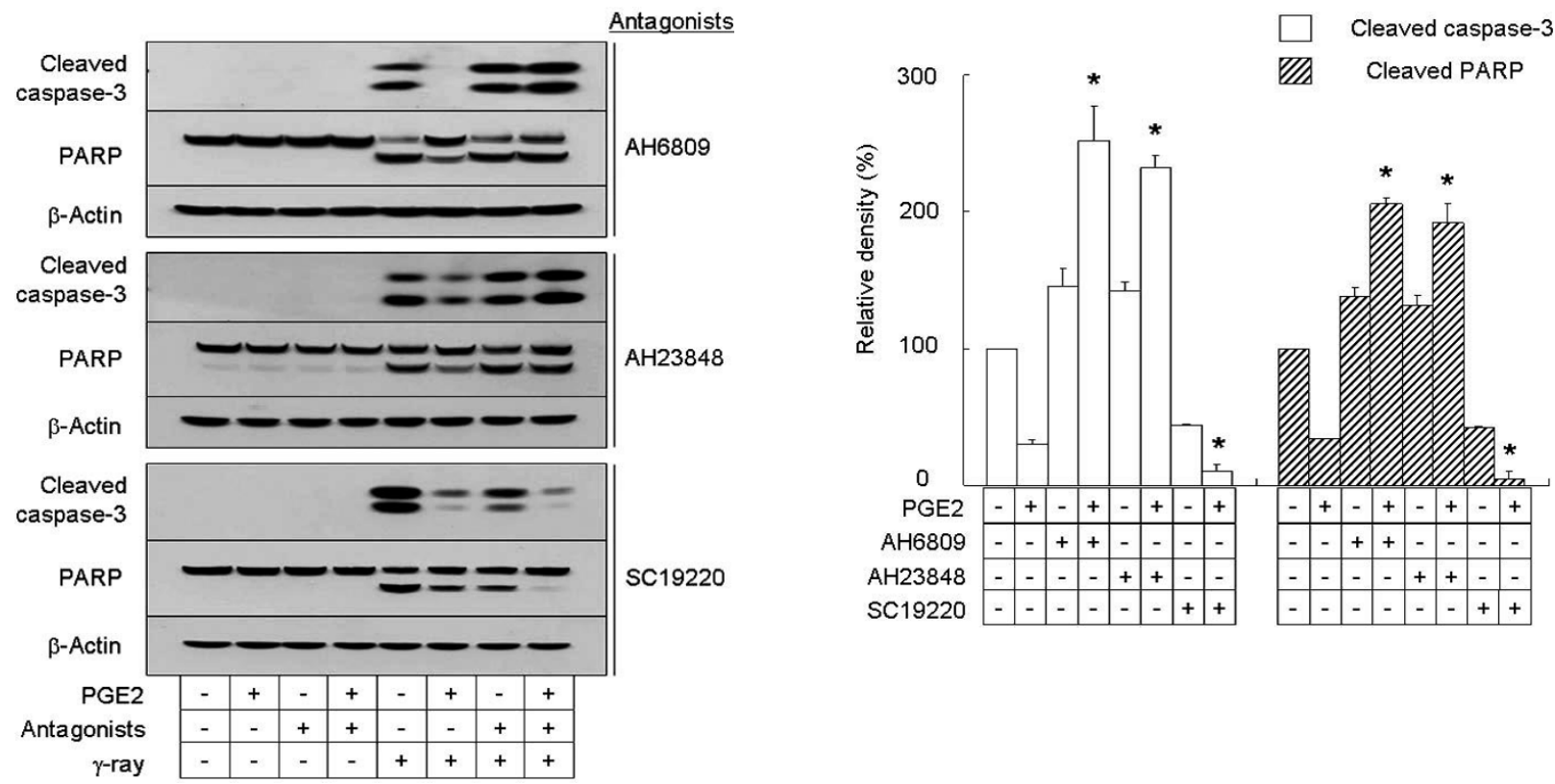

B
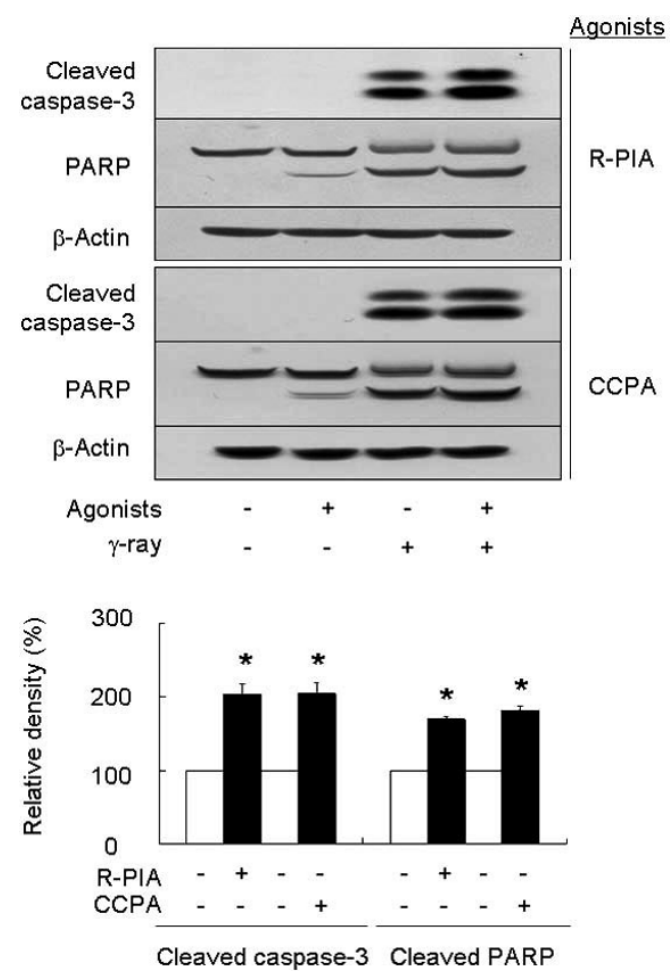

Figure 4. GPCR ligands regulated the gamma ray-induced apoptosis of SH-SY5Y human neuroblastoma cells. (A) Effects of PGE2 on gamma ray-induced apoptosis. SH-SY5Y cells were pretreated with $10 \mu \mathrm{M}$ PGE2, AH6809, AH23848 and SC19220 for 30 min before gamma ray exposure (4 Gy) and then cells were harvested after $24 \mathrm{~h}$. (B) Effects of adenosine A1 agonists on gamma ray-induced apoptosis. SH-SY5Y cells were pretreated with $10 \mu \mathrm{M}$ R-PIA or CCPA for 30 min before gamma ray irradiation (4 Gy) for $24 \mathrm{~h}$. Apoptosis was assessed by Western analysis for cleavages of caspase- 3 and PARP in SH-SY5Y cells, and the blots shown are representative of at least three independent experiments. Data are expressed as percentages of corresponding densities for gamma ray-irradiated cells and the histograms represent mean \pm SE. Asterisks indicate significant differences $(P<0.05$ versus control cells, Mann-Whitney U-test). 
EP4 prostanoid antagonist, increased gamma ray-induced caspase- 3 cleavage to $233.0 \pm 7.8 \%$ $(P<0.05)$, and PARP cleavage to $192.1 \pm 13.9 \%$ $(P<0.05)$, respectively. On the other hand, co-treatment of PGE2 together with SC19220, an antagonist specific for EP1 prostanoid receptor that activates inhibitory $G$ proteins $(G \alpha i 2)$ to inhibit adenylate cyclase, decreased the gamma ray-induced caspase-3 cleavage to $10.5 \pm 4.9 \%$ $(P<0.05)$ and PARP cleavage to $4.6 \pm 6.0 \%(P$

0.05) in PGE2-treated cells (Figure 4A). Furthermore, treatment of SH-SY5Y cells with R-PIA and CCPA, agonists for adenosine A1 receptor that also activates $\mathrm{G} \alpha \mathrm{i} 2$ to inhibit adenylate cyclases, increased gamma ray-induced apoptosis. Pretreatment with R-PIA augmented caspase-3 cleavage to $203.9 \pm 13.0 \%(P<0.05)$ and PARP cleavage to $169.6 \pm 4.4 \%(P<0.05)$, respectively, and pretreatment with CCPA also augmented caspase-3 cleavage to $204.5 \pm 14.4 \%$ $(P<0.05)$, and PARP cleavage to $181.6 \pm 6.7 \%$ $(P<0.05)$ (Figure 4B). This result indicates that GPCR agonists and antagonist coupled to Gos/ Gai-cAMP signaling pathway can regulate gamma ray-induced apoptosis.

\section{Discussion}

This study was performed to investigate the molecular mechanism for Gas-cAMP signaling pathways to inhibit radiation-induced apoptosis, and we found that Gas inhibits gamma ray-induced apoptosis by restraining down-regulation of $\mathrm{Bcl}-\mathrm{xL}$ in SH-SY5Y human neuroblastoma cells. This finding is supported by the result that stable expression of constitutively active GasQL inhibited gamma ray-induced apoptosis, which was assessed by cleavage of caspase- 9 , caspase- 3 and PARP, cytochrome $C$ release, and FACS analysis of Annexin V-stained cells. Second, expression of GasQL preserved $\mathrm{Bcl}-\mathrm{xL}$ level by reducing the degradation rate of both $\mathrm{Bcl}-\mathrm{xL}$ protein and $\mathrm{mRNA}$ following gamma ray irradiation. Third, blocking of $\mathrm{Bcl}-\mathrm{xL}$ expression by treatment with $\mathrm{Bcl}-\mathrm{xL}$ siRNA abolished the inhibitory effects of $\mathrm{G} \alpha \mathrm{s}$ on gamma ray-induced apoptosis. Finally, pretreatment with PGE2 that activates Gas also inhibited gamma ray-induced apoptosis via Gas-coupled receptor subtype dependent pathways.

lonizing radiation induces DNA damages to cause cell death by various mechanisms including apoptosis. During radiation-induced apoptosis, a variety of signaling pathways are activated to regulate the activity of apoptosis-related molecules. Ionizing radiation has been reported to increase in the activity of pro-apoptotic Bax in contrast to decrease in that of anti-apoptotic Bcl-2 family including Bcl-2 and Bcl-xL (Findley et al., 1997). cAMP signaling has been known to exert a protective effect against radiation-induced cell death for a long time (Lehnert, 1975), and has been reported to inhibit radiation-induced apoptosis by up-regulation of $\mathrm{Bcl}-2$ expression which prevent activation of capase- 9 by inhibiting the release of cytochrome $\mathrm{C}$ from mitochondria into the cytosol (Srivastava et al., 1998). The inhibition of PKA was reported to have a cooperative anti-tumor effect with radiotherapy and to cause inactivation of $\mathrm{Bcl}-2$ which eventually leads to induction of apoptosis (Tortora and Ciardiello, 2002). The promoter of Bcl-2 gene contains cyclic AMP response element (CRE) that enables CAMP signaling pathway to up-regulate the $\mathrm{Bcl}-2$ gene expression by CRE binding proteins (CREB) (Wilson et al., 1996). However, the effects of cAMP signaling system on the expression of $\mathrm{Bcl}-\mathrm{xL}$, another antiapoptotic Bcl-2 family protein, following exposure to ionizing radiation has not been reported yet, and in this study we shows that Gas-cAMP signaling system can protect radiation-induced apoptosis by up-regulating the expression of $\mathrm{BCl}-\mathrm{xL}$, indicating another mechanism for CAMP signaling pathway to protect radiation-induced apoptosis. This finding agrees well with the report that treatment with a cAMP analogue, sp-5,6-DCl-BIMPS, was found to suppress apoptosis by restraining the Bcl-xL downregulation in CD34(+) cells (Negrotto et al., 2006). The alpha subunit of stimulatory $G$ protein $(\mathrm{G} \alpha \mathrm{s}$ ) activates adenylate cyclase to increase cellular cAMP, which in turn activates signaling pathway that has been reported to regulate apoptosis in a variety of cell types and neurons including $\mathrm{SH}$ SY5Y human neuroblastoma cells. However, cAMP signaling system has been reported to stimulate apoptosis in some type of cells, suggesting that CAMP signaling system inhibits or stimulates apoptosis depending on the cell types and on the nature of apoptosis-triggering agents.

In humans, Bcl-x encodes two distinct species of mRNA designated $\mathrm{Bcl}-\mathrm{xL}$ and $\mathrm{Bcl}-\mathrm{xS}$. The protein product of the longer transcript, $\mathrm{Bcl}-\mathrm{xL}$ can inhibit apoptosis in tumor cell lines but, the smaller transcript, Bcl-xS can act as a dominant facilitator of cell death (Boise et al., 1993). The anti-apoptotic Bcl-2 members including $\mathrm{Bcl}-\mathrm{xL}$ prevent mitochondrial protein release by interacting with and inhibiting both Bak/Bax and BH3-only proteins. When Bad heterodimerizes with $\mathrm{Bcl}-\mathrm{xL}$ in mammalian cells, it releases $\mathrm{Bax}$ from $\mathrm{Bcl}-\mathrm{xL}$ complex, which results in the cytochrome $C$ release to promote cell death (Oltvai et al., 1993; Yang et al., 1995, 2006). The 
relative levels and competing dimerization between $\mathrm{Bcl}-2$ family members can indirectly prevent the activation of executioner caspases by controlling cytochrome $C$ efflux from mitochondria. In particular, Bax interacts with mitochondrial membrane allowing cytochrome $\mathrm{c}$ release, whereas $\mathrm{Bcl}-2$ and $\mathrm{Bcl}-\mathrm{xL}$ act in the opposite way, interfering with the activation of Bax (Yang et al., 1995).

Interestingly, $\mathrm{Bcl}-\mathrm{xL}$ but not $\mathrm{Bcl}-\mathrm{xS}$ is highly expressed in neuroblastoma cell lines. Moreover, $\mathrm{Bcl}-\mathrm{xL}$ contributes to pleiotropic drug resistance in neuroblastoma tumors by inhibiting chemotherapyinduced apoptosis, and Bcl-xL over-expression protects radiation-induced apoptosis in many cancer cell lines (Dole et al., 1995; Taylor et al., 1999). These reports indirectly support our finding that Gas-cAMP signaling system can exert a protective effect against ionizing radiation-induced apoptosis by inducing $\mathrm{Bcl}-\mathrm{xL}$ expression.

In a study to probe the mechanism for $G \alpha s$ to restrain $\mathrm{Bcl}-\mathrm{xL}$ down-regulation, we found that $\mathrm{G} \alpha \mathrm{S}$ slows down the degradation of both Bcl-xL mRNA and protein following gamma ray irradiation. Similar restraining of $\mathrm{Bcl}-\mathrm{XL}$ down-regulation by cAMP signaling system was reported in serum deprivation-induced apoptosis in CD34+-derived megakaryocytes (Negrotto et al., 2006). Gas was found to restrain the Bcl-xL mRNA down-regulation after blocking transcription by actinomycin treatment, and to slow down the degradation of $\mathrm{Bcl}-\mathrm{xL}$ mRNA, suggesting that $G \alpha s$ increase stability of $\mathrm{Bcl}-\mathrm{xL} \mathrm{mRNA}$ to restrain $\mathrm{Bcl}-\mathrm{xL}$ down-regulation. However, the mechanism for Gas to increase the stability of Bcl-xL mRNA needs to be elucidated. Furthermore, the effects of Gas on the transcription of $\mathrm{Bcl}-\mathrm{xL}$ cannot be excluded because more mRNA was maintained in the cells that were not treated with actinomycin $D$, after gamma ray irradiation. In addition to stabilization of $\mathrm{Bcl}-\mathrm{xL}$ mRNA, Gas signaling system was found to slow down the degradation of $\mathrm{Bcl}-\mathrm{xL}$ protein, which also can contribute to maintain a higher protein level required for anti-apoptotic effect of Gas-cAMP system. Thus, this study shows that Gas-cAMP signaling system protects SH-SY5Y neuroblastoma cells by slowing down Bcl-xL mRNA and protein following gamma ray-irradiation. Moreover, Gas was found to represse ionizing radiation-induced up-regulation of Bak in SH-SY5Y human neuroblastoma cells, which also favors cell survival (Choi et al., 2006), indicating Gas-cAMP signaling system protects cells against radiation-induced apoptosis by affecting multiple pro-apoptotic and anti-apoptotic $\mathrm{Bcl}-2$ family proteins.

This study also shows that radiation-induced apoptosis can be modulated by the ligands for
GPCR that activates $G \alpha s$ or $G \alpha i$ to regulate adenylate cyclase activity and thus CAMP levels. This finding is supported by the result that treatment with PGE2 that binds to Gas-coupled receptor protected gamma ray-induced apoptosis in SH-SY5Y cells. PGE2 binds to four different receptor subtypes termed EP1, EP2, EP3 and EP4, among which EP2 and EP4 receptors couple to a Gas (Hata and Breyer, 2004). The protective effect of $\mathrm{G} \alpha \mathrm{s}$ against gamma ray-induced apoptosis was abolished by treatment with specific EP2/4R antagonist such as AH6809 and AH23848, but treatment with an antagonist of EP1 receptor that couples to $\mathrm{G} \alpha \mathrm{i}$ to inhibit adenylate cyclases decreased the apoptosis. In the same vein, treatment with R-PIA and CCPA, agonists for adenosine $A 1$ receptor that also activate $G \alpha i$ to inhibit adenylate cyclases, augmented ionizing radiationinduced apoptosis of the SH-SY5Y neuroblastoma cells. Adenosine receptors are major targets of caffeine, and there is growing evidence that they could also be promising therapeutic targets in a wide range of conditions, including cancer (Jacobson and Gao, 2006). Our finding agrees well with the reports that PGE2 protects against apoptosis of human colon cancer cells (Sheng et al., 1998), and thus EP receptors have been identified as potential targets for treatment and prevention of colorectal cancer. The anti-apoptotic effect of PGE2 and pro-apoptotic effect of adenosine $A 1$ can result from the modulation of $G \alpha s /$ Gai-cAMP signaling pathway that regulates expression of various apoptosis-related molecules including $\mathrm{Bcl}-\mathrm{xL}$. This finding suggests that the therapeutic efficiency of cancer radiotherapy can be improved by co-treatment with specific GPCR ligands that inhibits Gas-cAMP signaling system to reduce the resistance to radiation-induced apoptosis.

From this study, it is concluded that Gas can protect SH-SY5Y neuroblastoma cells from gamma ray-induced apoptosis partly by restraining $\mathrm{Bcl}-\mathrm{xL}$ down-regulation, which can be modulated by the ligands of various receptors that couple to $G \alpha s$ or Gai. This finding provides a better understanding how Gas signaling pathways modulate gamma ray-induced apoptosis, and an important clinical implications that the efficiency of radiation therapy against cancer cells could be improved by modulation of Gas/Gai-cAMP signaling system with agonists or antagonists for cancer-cell specifically expressed GPCR.

\section{Acknowledgments}

This work was supported by a grant (No. M205090053990 
6B090039910) from Nuclear R\&D Program of the ministry of Science and Technology.

\section{References}

Ahn YH, Koh JY, Hong SH. Protein synthesis-dependent but $\mathrm{Bcl}$-2-independent cytochrome $\mathrm{C}$ release in zinc depletioninduced neuronal apoptosis. J Neurosci Res 2000;61:50814

Boise LH, Gonzalez-Garcia M, Postema CE, Ding L, Lindsten T, Turka LA, Mao X, Nunez G, Thompson C B. bcl-x, a bcl-2-related gene that functions as a dominant regulator of apoptotic cell death. Cell 1993;74:597-608

Chin C, Bae JH, Kim MJ, Hwang JY, Kim SJ, Yoon MS, Lee MK, Kim DW, Chung BS, Kang CD, Kim SH. Radiosensitization by targeting radioresistance-related genes with protein kinase A inhibitor in radioresistant cancer cells. Exp Mol Med 2005;37:608-18

Cho $\mathrm{CH}$, Seo M, Lee YI, Kim SY, Youn HD, Juhnn YS. Dibutyryl cAMP stimulates the proliferation of SH-SY5Y human neuroblastoma cells by up-regulating Skp2 protein. J Cancer Res Clin Oncol 2007;133:135-44

Choi SY, Kim MJ, Kang CM, Bae S, Cho CK, Soh JW, Kim $\mathrm{JH}$, Kang S, Chung HY, Lee YS, Lee SJ. Activation of Bak and Bax through c-abl-protein kinase Cdelta-p38 MAPK signaling in response to ionizing radiation in human nonsmall cell lung cancer cells. J Biol Chem 2006;281:7049-59

Dole MG, Jasty R, Cooper MJ, Thompson CB, Nunez G, Castle VP. Bcl-xL is expressed in neuroblastoma cells and modulates chemotherapy-induced apoptosis. Cancer Res 1995;55:2576-82

Findley HW, Gu L, Yeager AM, Zhou M. Expression and regulation of $\mathrm{Bcl}-2, \mathrm{Bcl}-\mathrm{xl}$, and $\mathrm{Bax}$ correlate with $\mathrm{p} 53$ status and sensitivity to apoptosis in childhood acute lymphoblastic leukemia. Blood 1997;89:2986-93

Gilman AG. G proteins: transducers of receptor-generated signals. Annu Rev Biochem 1987;56:615-49

Hata AN, Breyer RM. Pharmacology and signaling of prostaglandin receptors: multiple roles in inflammation and immune modulation. Pharmacol Ther 2004;103:147-66

Huang DC, Cory S, Strasser A. Bcl-2, Bcl-XL and adenovirus protein E1B19kD are functionally equivalent in their ability to inhibit cell death. Oncogene 1997;14:405-14

Jacobson KA, Gao ZG. Adenosine receptors as therapeutic targets. Nat Rev Drug Discov 2006;5:247-64

Jang IS, Juhnn YS. Adaptation of cAMP signaling system in SH-SY5Y neuroblastoma cells following expression of a constitutively active stimulatory G protein alpha, Q227L Gsalpha. Exp Mol Med 2001;33:37-45

Koyama H, Bornfeldt KE, Fukumoto S, Nishizawa Y. Molecular pathways of cyclic nucleotide-induced inhibition of arterial smooth muscle cell proliferation. J Cell Physiol 2001;186:1-10

Lehnert S. Modification of postirradiation survival of mammalian cells by intracellular cyclic AMP. Radiat Res 1975;62: 107-16

Lewerenz J, Letz J, Methner A. Activation of stimulatory heterotrimeric $\mathrm{G}$ proteins increases glutathione and protects neuronal cells against oxidative stress. J Neurochem 2003;87:522-31

McCudden CR, Hains MD, Kimple RJ, Siderovski DP, Willard FS. G-protein signaling: back to the future. Cell Mol Life Sci 2005;62:551-77

Morrison DJ, English MA, Licht JD. WT1 induces apoptosis through transcriptional regulation of the proapoptotic Bcl-2 family member Bak. Cancer Res 2005;65:8174-82

Neer EJ. Heterotrimeric G proteins: organizers of transmembrane signals. Cell 1995;80:249-57

Negrotto S, Pacienza N, D'Atri LP, Pozner RG, Malaver E, Torres O, Lazzari MA, Gomez RM, Schattner M. Activation of cyclic AMP pathway prevents CD34(+) cell apoptosis. Exp Hematol 2006;34:1420-8

Oltvai ZN, Milliman CL, Korsmeyer SJ. Bcl-2 heterodimerizes in vivo with a conserved homolog, Bax, that accelerates programmed cell death. Cell 1993;74:609-19

Sheng H, Shao J, Morrow JD, Beauchamp RD, DuBois RN. Modulation of apoptosis and Bcl-2 expression by prostaglandin E2 in human colon cancer cells. Cancer Res 1998; 58:362-6

Srivastava RK, Srivastava AR, Korsmeyer SJ, Nesterova M, Cho-Chung YS, Longo DL. Involvement of microtubules in the regulation of $\mathrm{Bcl} 2$ phosphorylation and apoptosis through cyclic AMP-dependent protein kinase. Mol Cell Biol 1998; 18:3509-17

Taylor JK, Zhang QQ, Monia BP, Marcusson EG, Dean NM. Inhibition of Bcl-xL expression sensitizes normal human keratinocytes and epithelial cells to apoptotic stimuli. Oncogene 1999;18:4495-504

Tortora G, Ciardiello F. Protein kinase A as target for novel integrated strategies of cancer therapy. Ann N Y Acad Sci 2002;968:139-47

Wilson BE, Mochon E, Boxer LM. Induction of bcl-2 expression by phosphorylated CREB proteins during B-cell activation and rescue from apoptosis. Mol Cell Biol 1996; 16:5546-56

Yang E, Zha J, Jockel J, Boise LH, Thompson CB, Korsmeyer SJ. Bad, a heterodimeric partner for $\mathrm{Bcl}-\mathrm{XL}$ and $\mathrm{Bcl}-2$, displaces Bax and promotes cell death. Cell 1995;80:285-91

Yang SH, Chien CM, Lu MC, Lin YH, Hu XW ,Lin SR. Up-regulation of Bax and endonuclease $\mathrm{G}$, and downmodulation of $\mathrm{Bcl}-\mathrm{XL}$ involved in cardiotoxin III-induced apoptosis in K562 cells. Exp Mol Med 2006;38:435-44 